\title{
Artificial Neural Networks for Predicting Hydrogen Production in Catalytic Dry Reforming: A Systematic Review
}

\author{
Van Thuan Le ${ }^{1,2}\left(\mathbb{D}\right.$, Elena-Niculina Dragoi ${ }^{3}\left(\mathbb{D}\right.$, Fares Almomani ${ }^{4, *(D)}$ and Yasser Vasseghian ${ }^{1,2}(\mathbb{D}$ \\ 1 Center for Advanced Chemistry, Institute of Research and Development, Duy Tan University, \\ Da Nang 550000, Vietnam; levanthuan3@duytan.edu.vn (V.T.L.); yasservasseghian@duytan.edu.vn (Y.V.) \\ 2 The Faculty of Environmental and Chemical Engineering, Duy Tan University, Da Nang 550000, Vietnam \\ 3 Faculty of Chemical Engineering and Environmental Protection "Cristofor Simionescu", \\ "Gheorghe Asachi" Technical University, 700050 Iasi, Romania; elena.dragoi@tuiasi.ro \\ 4 Department of Chemical Engineering, College of Engineering, Qatar University, Doha P.O. Box 2713, Qatar \\ * Correspondence: falmomani@qu.edu.qa
}

check for

updates

Citation: Le, V.T.; Dragoi, E.-N.;

Almomani, F.; Vasseghian, Y.

Artificial Neural Networks for

Predicting Hydrogen Production in

Catalytic Dry Reforming: A

Systematic Review. Energies 2021, 14 ,

2894. https://doi.org/10.3390/

en14102894

Academic Editors: Vladislav

A. Sadykov and Attilio Converti

Received: 14 March 2021

Accepted: 5 May 2021

Published: 17 May 2021

Publisher's Note: MDPI stays neutral with regard to jurisdictional claims in published maps and institutional affiliations.

Copyright: (C) 2021 by the authors. Licensee MDPI, Basel, Switzerland. This article is an open access article distributed under the terms and conditions of the Creative Commons Attribution (CC BY) license (https:/ / creativecommons.org/licenses/by/ $4.0 /)$.

\begin{abstract}
Dry reforming of hydrocarbons, alcohols, and biological compounds is one of the most promising and effective avenues to increase hydrogen $\left(\mathrm{H}_{2}\right)$ production. Catalytic dry reforming is used to facilitate the reforming process. The most popular catalysts for dry reforming are Ni-based catalysts. Due to their inactivation at high temperatures, these catalysts need to use metal supports, which have received special attention from researchers in recent years. Due to the existence of a wide range of metal supports and the need for accurate detection of higher $\mathrm{H}_{2}$ production, in this study, a systematic review and meta-analysis using ANNs were conducted to assess the hydrogen production by various catalysts in the dry reforming process. The Scopus, Embase, and Web of Science databases were investigated to retrieve the related articles from 1 January 2000 until 20 January 2021. Forty-seven articles containing 100 studies were included. To determine optimal models for three target factors (hydrocarbon conversion, hydrogen yield, and stability test time), artificial neural networks (ANNs) combined with differential evolution (DE) were applied. The best models obtained had an average relative error for the testing data of $0.52 \%$ for conversion, $3.36 \%$ for stability, and $0.03 \%$ for yield. These small differences between experimental results and predictions indicate a good generalization capability.
\end{abstract}

Keywords: hydrogen production; dry reforming; catalyst; meta-analysis; artificial neural network

\section{Introduction}

Global warming is one of the most important research topics today. Global warming is due to the excessive use of fossil fuel sources such as oil, natural gas, coal, etc., as well as the increase in greenhouse gas emissions [1-3]. Methane and $\mathrm{CO}_{2}$ are the most abundant greenhouse gases and are major factors in recent climate change. Although the concentration of methane in the atmosphere is much lower than that of $\mathrm{CO}_{2}$, it has surprisingly led to about $20 \%$ of global warming [4]. One of the most important sources of methane emissions is human activities including oil, gas, and coal extraction as well as landfilling. About one-third of US-produced methane is emitted from landfills according to the US Environmental Protection Agency (EPA) [5]. In recent years, the use of hydrogen $\left(\mathrm{H}_{2}\right)$ as a clean fuel to solve the energy crises and environmental challenges has increased. Currently, about $95 \%$ of all $\mathrm{H}_{2}$ production comes from fossil fuels due to lower costs [6-8]. There are currently several methods for $\mathrm{H}_{2}$ production, including steam reforming of hydrocarbons (SRH), dry reforming of hydrocarbons (DRH), and partial oxidation of hydrocarbons $(\mathrm{POH})$. Among these processes, DRH is preferred because it is cheap, pro-industry, and ecofriendly [9]. DRH, especially by methane (DRM), not only leads to the elimination of greenhouse gases, but the appropriate $\mathrm{CO} / \mathrm{H}_{2}$ ratio can also be used directly as a crude 
gas for Fisher-Tropes synthesis [10]. The main and side reactions in DRM to produce $\mathrm{H}_{2}$ are in Equations (1)-(3) [11]:

$$
\begin{aligned}
\mathrm{CO}_{2}(\mathrm{~g})+\mathrm{CH}_{4}(\mathrm{~g}) & \rightarrow 2 \mathrm{CO}(\mathrm{g})+2 \mathrm{H}_{2}(\mathrm{~g}), \quad \Delta \mathrm{H}=257 \mathrm{~kJ} / \mathrm{mol} \\
& \mathrm{CH}_{4}(\mathrm{~g}) \rightarrow \mathrm{C}+2 \mathrm{H}_{2}(\mathrm{~g}) \\
& 2 \mathrm{CO}(\mathrm{g}) \rightarrow \mathrm{C}+\mathrm{CO}_{2}(\mathrm{~g})
\end{aligned}
$$

The DRM reaction is exothermic and operates at relatively high temperatures. Therefore, current research is mainly focused on the synthesis of highly efficient and stable catalysts for the DRM reaction [12]. Currently, the most popular catalysts for the DRM reaction are Ni-based catalysts, which are considered a good alternative to noble metals due to their good catalytic performance, availability, and low reaction cost [13]. However, these catalysts create a worrying problem: the deactivation of the catalyst. Carbon formation and high-temperature sintering are the main reasons for the deactivation of these catalysts. Coke formation by two side reactions in DRM is involved in both methane cracking (Equation (2)) and the Boudouard reaction (Equation (3)). Sintering of the active sites of the catalyst material is due to the high reaction temperature of between $773.15 \mathrm{~K}$ and $1273.15 \mathrm{~K}$ [14]. Therefore, to develop carbon resistance in Ni-based catalysts, the addition of a non-noble metal, the best candidate being cobalt (Co), is the most effective economic solution. However, Co has relatively low catalytic performance compared to Ni-based catalysts [15]. To solve this problem, support materials can be used. In recent years, catalysts supported by carbon (C), tin (Sn), manganese (Mg), and aluminum (Al)-based materials have been extensively investigated for DRM reactions [5]. These supports are widely used in catalytic reactions due to their specific surface area, higher stability, and low cost. Their high stability and specific surface can greatly improve the dispersibility and stability of activated metals. However, the acidic sites in these support materials make the Co-based catalyst prone to reduced $\mathrm{CO}_{2}$ uptake and activation, resulting in poor catalytic performance [16]. Therefore, coupling of basic groups of alkali metals to these support materials is one of the most effective measures to compensate for the negative impact of acidic sites on the Co-based catalysts and accelerate the adsorption and activation of the reactant [4].

Currently, there are several methods to develop a catalyst with better catalytic performance for the DRM reaction, including improving the chemical properties of the support [16-18], designing a polymetallic catalyst $[19,20]$, and using appropriate promoters $[11,12,21,22]$. In all these methods, increasing the metal dispersion, improving the interaction between the active metal and the catalyst support, minimizing sintering, and increasing the thermal stability are the most important features that should be considered when choosing a catalyst for the DRM reaction [23].

In recent years, most published research papers on $\mathrm{H}_{2}$ production in the DRH reaction have focused on developing a suitable catalyst for the reaction. However, there is no meta-analysis of their use for the $\mathrm{H}_{2}$ production in DRH reactions. Therefore, the present study conducted a systematic review that aimed to provide insights into the use of suitable hydrocarbons and alcohols, suitable catalysts, and suitable operating conditions in the dry reforming reaction to produce $\mathrm{H}_{2}$. This study also analyzed the data extracted from recent studies to produce $\mathrm{H}_{2}$ in the DRH reaction to evaluate their performance using artificial neural networks (ANNs) combined with differential evolution (DE). Finally, the applications and performance obtained using these catalysts in the DRH reaction are discussed.

\section{Search Strategy and the Protocol of the Study}

\subsection{Search Strategy}

To retrieve articles from 1 January 2000 until 20 January 2021 related to hydrogen production in the catalytic dry reforming of hydrocarbons according to the PRISMA guideline, searches were performed in the Scopus, Embase, and Web of Science databases [24,25]. The following keywords were included: "hydrogen", $\mathrm{OR}$ " $\mathrm{H}_{2}$ " OR "hydrogen production" $\mathrm{OR}$ " $\mathrm{H}_{2}$ production" AND "reforming", $\mathrm{OR}$ "dry reforming" $\mathrm{OR}$ "catalytic reforming" 
OR "catalytic dry reforming" OR "dry reforming of hydrocarbon" OR "dry reforming of methane" OR "DRH" OR "DRM". Initially, 851 articles were acquired. Then, based on a screening of titles and abstracts, 119 articles remained for full-text assessment. In the next stage, based on full-text evaluation, 50 articles with 100 cases regarding the utilization of hydrogen production in catalytic dry reforming of hydrocarbons and alcohols for data extraction were extracted (Figure 1, Table S1).

\subsection{Inclusion Criteria and Data Extraction}

The following criteria were marked for the inclusion of articles in the study: (1) dry reforming of a type of hydrocarbon, (2) catalytic dry reforming, (3) reforming used for hydrogen production, (4) published online between 1 January 2000 and 20 January 2021, (5) full text of the article was available, and (5) English. Review articles, books, book chapters, letters to the editor, and conferences were excluded. References to related articles for access to further articles were also evaluated [26,27].

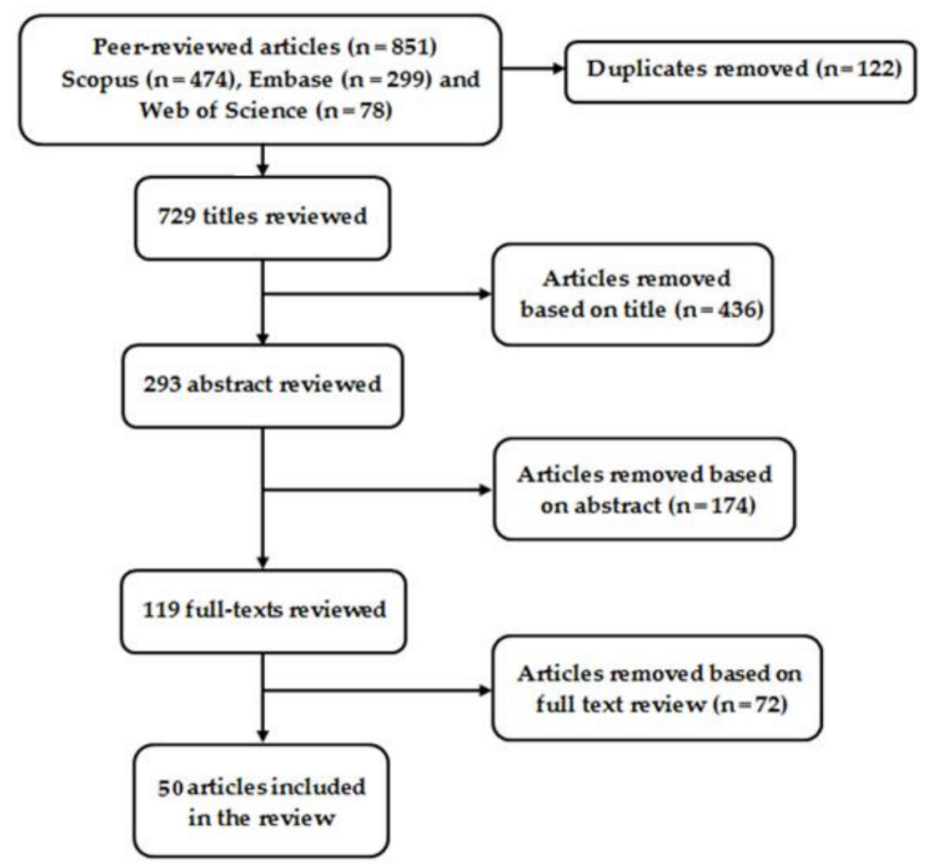

Figure 1. The screening of articles for hydrogen production in catalytic dry reforming according to PRISMA.

\subsection{Artificial Neural Network Modeling}

To model the different aspects of hydrogen production (\% of hydrocarbon conversion, yield, and stability test time), a methodology combining artificial neural networks (ANNs) and the differential evolution algorithm (DE) [28] was developed. The idea behind combining DE and ANNs is based on the difficulty of determining an optimal ANN, a problem that is influenced by the characteristics of the system studied. One of the major advantages of this combination is that it relies on the ability to escape a local optimum, making it robust and adaptable to changing environments $[29,30]$. The combination of an evolutionary algorithm such as DE with ANNs is known as neuro-evolution and depending on the characteristics evolved, three main classes are encountered: (i) evolving weights; (ii) evolving architecture; and (iii) evolving both simultaneously [31]. The methodology proposed in this work focuses on architecture evolution, with this aspect being equivalent to finding the highest point on the surface [32]. Compared to constructive or destructive methods, the evolutionary algorithms are better suited because the surface is unlimited, not differentiable (changes in neurons or connections are discrete and have a dissentious effect on the ANN performance), complex and noisy, deceptive (similar ANN architectures 
can have different performance), and multimodal (distinct ANN architectures can have similar performance) [32,33]. Taking all of these aspects into account in the current work, DE evolves the architecture (number of layers and neurons in each hidden layer) and the resulted models are evaluated after being trained using the tools provided by the Keras library. The overall approach (Figure 2) was implemented in Python 3.7.4.

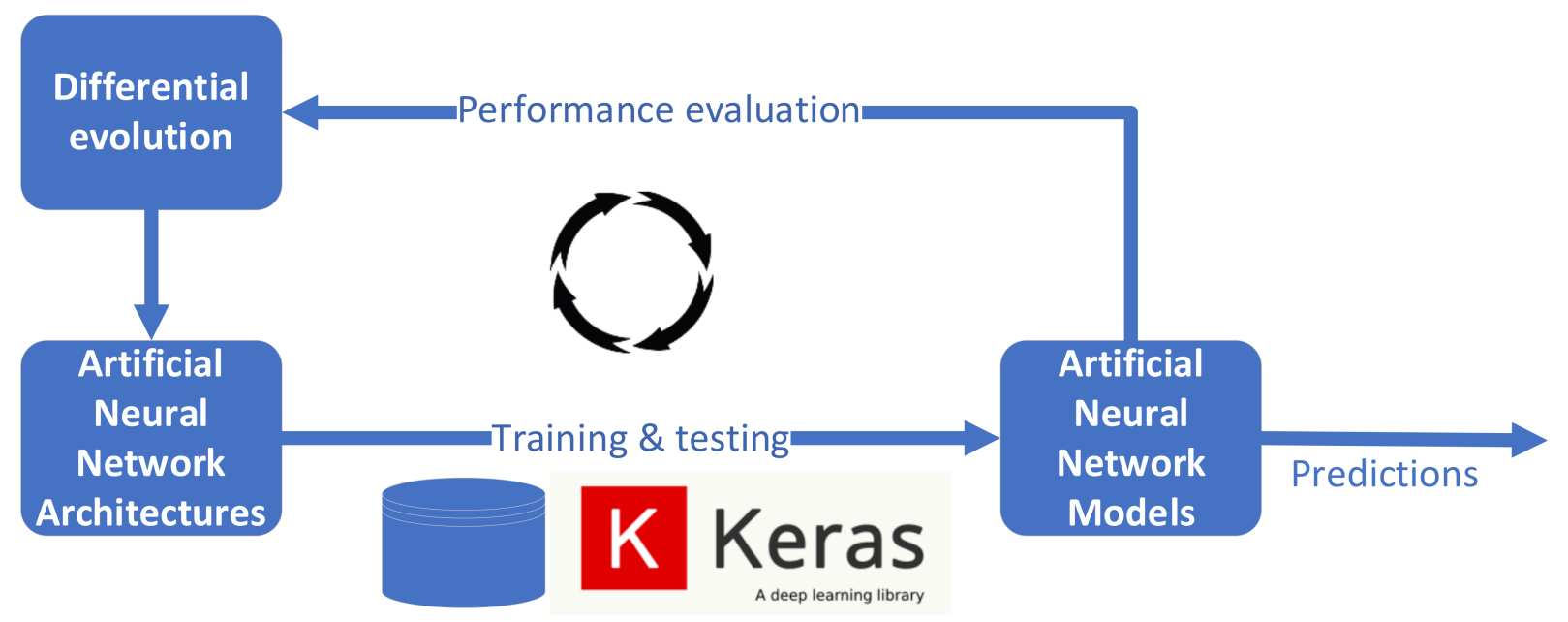

Figure 2. Schema of the ANN-based modeling.

First, the DE algorithm generated a series of encoded ANN architectures. These architectures were then loaded into the Keras and ANN models with the following characteristics: inputs and outputs layers with linear activation functions and number of neurons as determined by the dataset used, hidden layers with ReLu activations functions, and the number of neurons as generated by the DE algorithm. All the layers were of dense type and the models created were sequential. Next, using the dataset describing the process, the Keras library was used to train and test the models. The training objective was to determine the internal parameters of the model so that the loss-measured as the mean squared error (MSE) between predictions and actual values-was minimized. For MSE computations, Equation (4) was used. For training: (i) the algorithm was Adam, a stochastic gradient descent method that uses adaptive estimations of first and second-order moments, (ii) the number of epochs was set to 30, (iii) the batch size was set 10, (iv) the validation data were set at $10 \%$ from the training data, and (v) the shuffling training data were set to true [34]. Before starting the program, the dataset was loaded into memory, shuffled, and split into training $(80 \%)$, validation (10\% from training), and testing $(10 \%)[35,36]$.

$$
\text { MSE }=\frac{1}{n} \sum_{i=1}^{n}\left(\text { Out }_{\text {experimental }}-\text { Out }_{\text {predicted }}\right)^{2}
$$

where $\mathrm{n}$ is the number data for which the MSE is computed, Out experimental is the value of the analyzed parameter from an experimental approach, and Out predicted $_{\text {is }}$ the ANN predicted value.

After the models were trained, the testing data were used to determine the generalization capability of the models. These results were then loaded into DE, which modified the architecture and re-applied the training process. The architecture modification in the DE algorithm was performed for each model by repeating the following steps: mutation, crossover, and selection for several generations. In the mutation phase, the current population of encoded ANNs was mutated through a differentiation process. The characteristics of the resulting individuals were combined with the characteristics of their corresponding individuals from the current population in a process called crossover. This new set of ANNs (trial population) was trained with the Adam approach and then evaluated to determine its fitness. In the next step, selection, the individuals with the best fitness from the trial and 
current population were selected to form the new population to undergo the evolutionary process. More details about DE can be found in the annotated sources $[28,37,38]$. As the changes performed by DE are small, when transforming the encoded data into an ANN architecture, due to the discrete property, there is the possibility that over the generations, the architecture will remain unchanged. When this happened, the corresponding trained model from the previous generation was loaded and further trained. In this manner, the performance of these models was improved.

\section{Results and Discussion}

\subsection{Data Accessibility}

Our study searched 851 studies including 474 from Scopus, 299 from Embase, and 78 from Web of Science from 1 January 2000 and 20 January 2021. After screening, we selected only 50 studies containing 100 samples, which provided information about catalytic dry reforming for $\mathrm{H}_{2}$ production (Figure 1), with the majority conducted in Malaysia, Saudi Arabia, and Brazil. Among the 100 published samples, (88/100 (88\%) were related to the dry reforming of methane $\left(\mathrm{CH}_{4}\right) ; 7 / 100(7 \%)$ dry reforming of ethanol $\left(\mathrm{C}_{2} \mathrm{H}_{5} \mathrm{OH}\right)$, and $5 / 100(5 \%)$ dry reforming of glycerol $\left(\mathrm{C}_{3} \mathrm{H}_{8} \mathrm{O}_{3}\right)$.

\subsection{Artificial Neural Network Modeling}

After the data were gathered, in order to be used in the modeling procedure, it was processed while taking into account the following aspects: (i) all cases with missing data were removed, (ii) the parameters with no variation were eliminated from the input list, and (iii) the text/categorical data were transformed into numerical inputs [39]. This transformation was applied to the type of hydrocarbon, type of alcohol, and type of catalyst. Thus, for the type of hydrocarbon and alcohol, three inputs were considered: number of carbon atoms, number of hydrogen atoms, and number of oxygen atoms. Conversely, for the type of catalyst, the three cases were considered to be either missing (0), based (2), or added (1) for the elements: $\mathrm{Ni}, \mathrm{Co}, \mathrm{Zr}, \mathrm{Ce}, \mathrm{Al}, \mathrm{Mg}, \mathrm{Rh}, \mathrm{La}$, and $\mathrm{Ru}$. In the end, this resulted in a database with 13 independent parameters (C, H, O, Ni, Co, Zr, Ce, Al, Mg, Rh, La, Ru, and reaction temperature) and 3 target factors (hydrocarbon conversion, hydrogen yield, and stability test time). For each of the target factors, the modeling procedure was applied separately with the DE algorithm using the following settings: number of iterations $=50$, number of individuals in the population $=25$, initial crossover factor $=0.7$, initial mutation rate $=0.5$, mutation type $=$ Current_to_best_1 $[40,41]$, and self-adaptation for the control parameters. These values were determined based on a set of preliminary runs performed to empirically determine and eliminate the conditions where overtraining might occur. Due to the stochastic nature of the DE algorithm, for each target factor, the simulations were repeated 10 times. The statistics for the obtained models on the normalized data are listed in Table 1, where ARE represents an average relative error (\%) and the topology uses ' $:$ ' to separate the neurons in each layer.

For the testing data, the ARE of the best models obtained for conversion was $0.52 \%$, for stability $3.36 \%$, and yield $0.03 \%$. In all the cases, the ARE was lower than $5 \%$, indicating that the obtained models have a good generalization capability and can be efficiently used to determine the potential behavior of other combinations for the considered independent parameters. A comparison between the predictions and the experimental data in the testing case is presented in Figure 3 for conversion, Figure 4 for stability, and Figure 5 for yield. These results indicate that the determined models can be further used to generate predictions and/or for process optimization. To this end, the best models are publicly available at https:/ / bit.ly/3b22YQc (accessed on 4 May 2021) and can be loaded using the load_model function from the Keras model library. After loading, without further training, the models can be used in various scenarios, and combinations can be pointed out as suitable for further analysis and experimental study. 
Table 1. Statistics of the models obtained for each target factor.

\begin{tabular}{ccccccc}
\hline \multirow{2}{*}{ Target Factor } & & \multicolumn{2}{c}{ Training } & \multicolumn{2}{c}{ Validation } & \multirow{2}{*}{ Topology } \\
\cline { 3 - 6 } & & MSE & ARE & MSE & ARE & \\
\hline \multirow{3}{*}{ Conversion } & Best & 0.011 & 0.084 & 0.05 & 0.169 & $13: 22: 10: 01$ \\
& Worst & 0.407 & 0.529 & 0.736 & 0.634 & $13: 7: 14: 6: 01$ \\
& Average & 0.132 & 0.269 & 0.223 & 0.319 & - \\
\hline \multirow{3}{*}{ Stability } & Best & 0.001 & 0.027 & 0.002 & 0.044 & $13: 23: 01: 01$ \\
& Worst & 0.383 & 0.514 & 0.775 & 0.867 & $13: 24: 01$ \\
& Average & 0.080 & 0.142 & 0.164 & 0.237 & - \\
\hline \multirow{3}{*}{ Yield } & Best & 0.0001 & 0.015 & 0.001 & 0.02 & $13: 18: 01$ \\
& Worst & 0.017 & 0.111 & 0.07 & 0.234 & $13: 06: 01$ \\
& Average & 0.009 & 0.068 & 0.023 & 0.104 & - \\
\hline
\end{tabular}

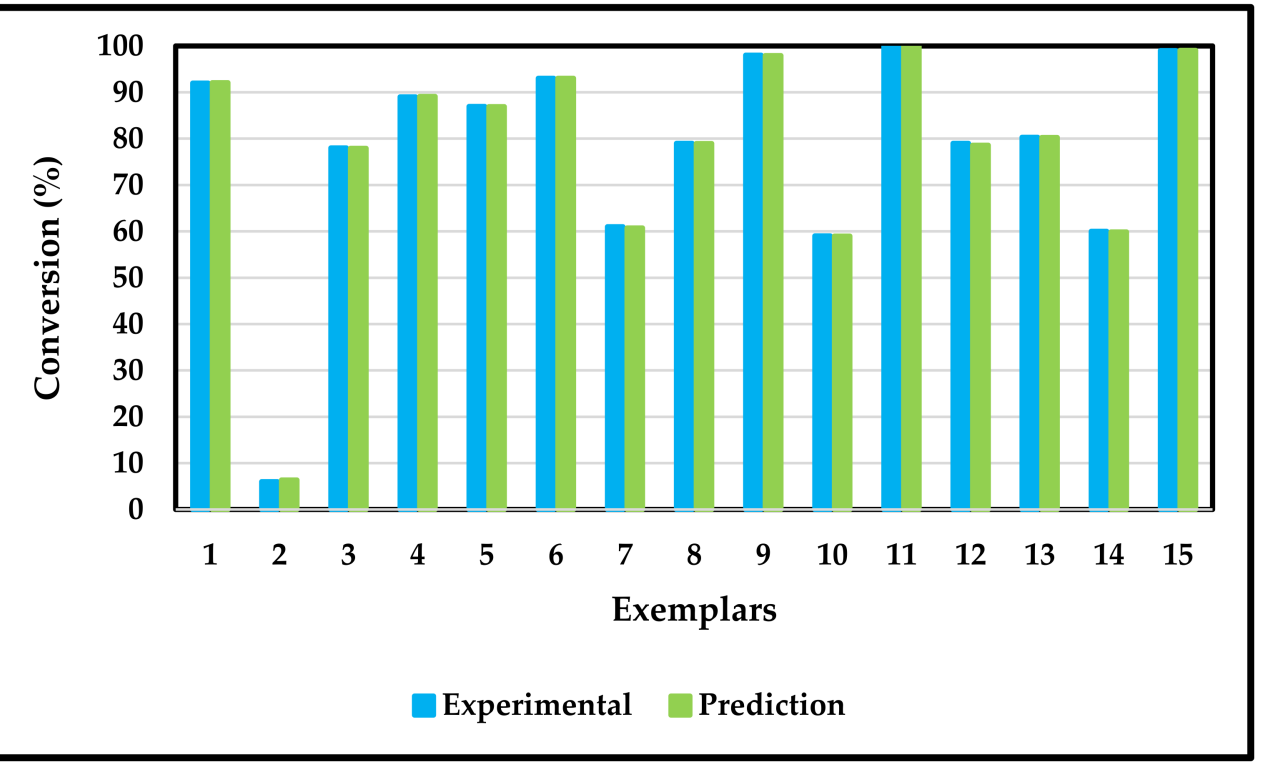

Figure 3. Comparison between the predictions and the experimental data in the testing case for conversion.

As shown in Figure 3, Ni-based catalysts showed higher conversion rates than those of other catalysts (for example, see Exemplars 9, 11, and 15). One of the main problems of catalysts in dry reforming is the inactivation of the catalyst due to the high rate of formation of carbon. Ni-based catalysts, due to more conversion of carbon than in other catalysts, have a high conversion rate, which also depends on the structure and composition of the catalyst. In recent years, the special properties of nanoparticles have led to attention for their use in the structure of catalysts in dry reforming. For example, nanocrystalline materials consisting of crystals with a size of 1 to 2 nanometers have a high surface-tovolume ratio, which produces several atoms with low coordination numbers at the edges and corners, which can create a large number of active sites. Bain and Kawi applied $\mathrm{Ni}-\mathrm{Co} / \mathrm{SiO}_{2}$ catalysts for dry reforming of methane. They synthesized Ni-Co alloy particles $(\sim 10 \mathrm{~nm})$ over silica. In this study, $10 \mathrm{Ni}$ and $7 \mathrm{Ni3Co}$ were illustrated with high and stable activity for $100 \mathrm{~h}$ DRM at $750{ }^{\circ} \mathrm{C}$ with $100 \%$ conversion [42]. In another study, Son et al. used $\mathrm{CoNi} / \mathrm{Al}_{2} \mathrm{O}_{3}$ and $\mathrm{MgCoNi} / \mathrm{Al}_{2} \mathrm{O}_{3}$ for $\mathrm{H}_{2}$ production from carbon dioxide reforming of methane. The results showed that the $\mathrm{MgCoNi} / \mathrm{Al}_{2} \mathrm{O}_{3}$ catalyst had a much higher conversion than that of the $\mathrm{CoNi} / \mathrm{Al}_{2} \mathrm{O}_{3}$ catalyst [20]. The reason for this can be attributed to the strong interaction between $\mathrm{Ni}$ and $\mathrm{MgO}, \mathrm{Mg}$ anti-carbon properties [43], and higher $\mathrm{MgO}$ reactivity in the carbon dioxide reforming [19]. 


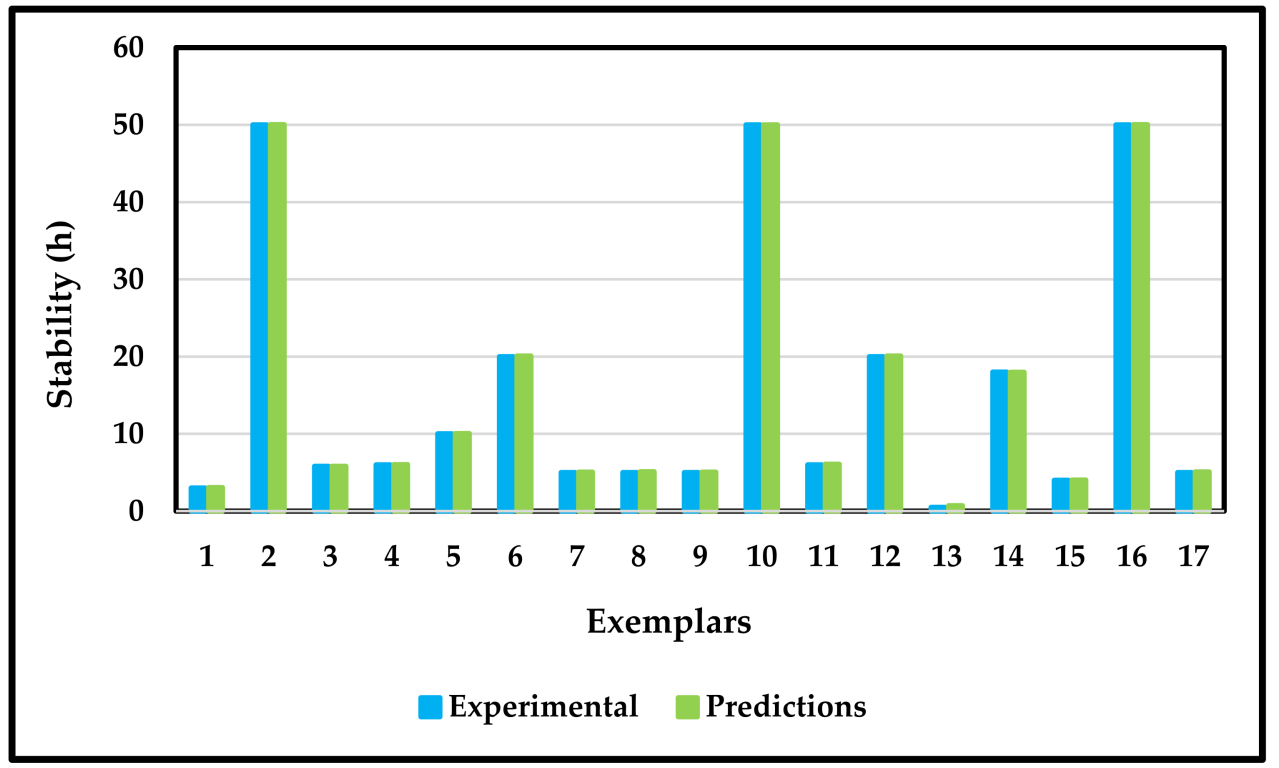

Figure 4. Comparison between the predictions and the experimental data in the testing case for stability.

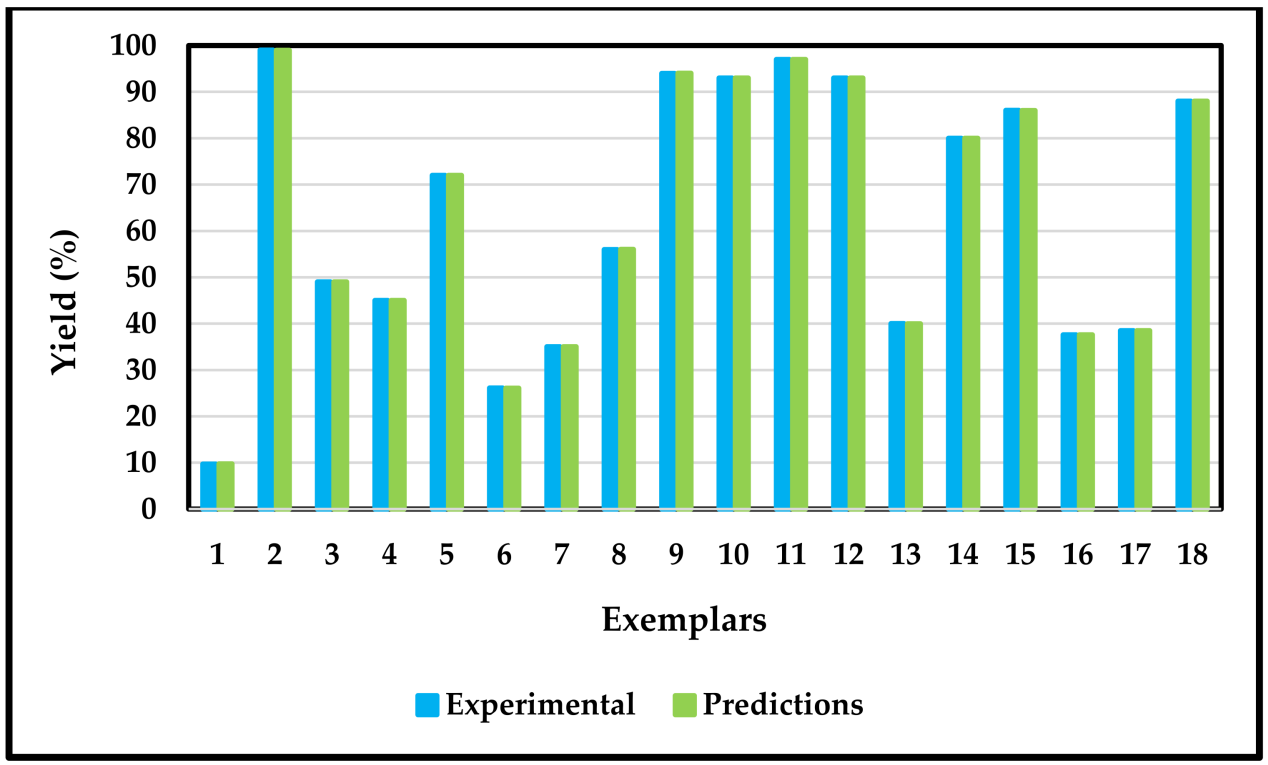

Figure 5. Comparison between the predictions and the experimental data in the testing case for yield.

The active metal is usually used as a supporting material for catalysts in dry reforming. These supports maximize the active sites by providing a wide area that increases the stability and yield of the process. In recent years, various supports such as $\mathrm{MgO}, \mathrm{ZnO} \mathrm{Al}_{2} \mathrm{O}_{3}, \mathrm{SiO}_{2}$, and $\mathrm{ZrO}_{2}$ have received special attention in catalytic dry reforming. To comprehend the impact of the support materials on stability and yield in catalytic dry reforming, Sokolov et al. employed a series of supported Ni catalysts in dry reforming of methane. In this study, N-based catalysis with Zr support showed a higher yield and stability than those of other supports (Figure 6) [44]. The reason for this can be attributed to high thermal stability, high surface area, and high relative activity for N-based catalysts with Zr support. Similar results were obtained in the present study, for example, Exemplar 4 in Figure 4 and Exemplars 11 and 12 in Figure 5. 


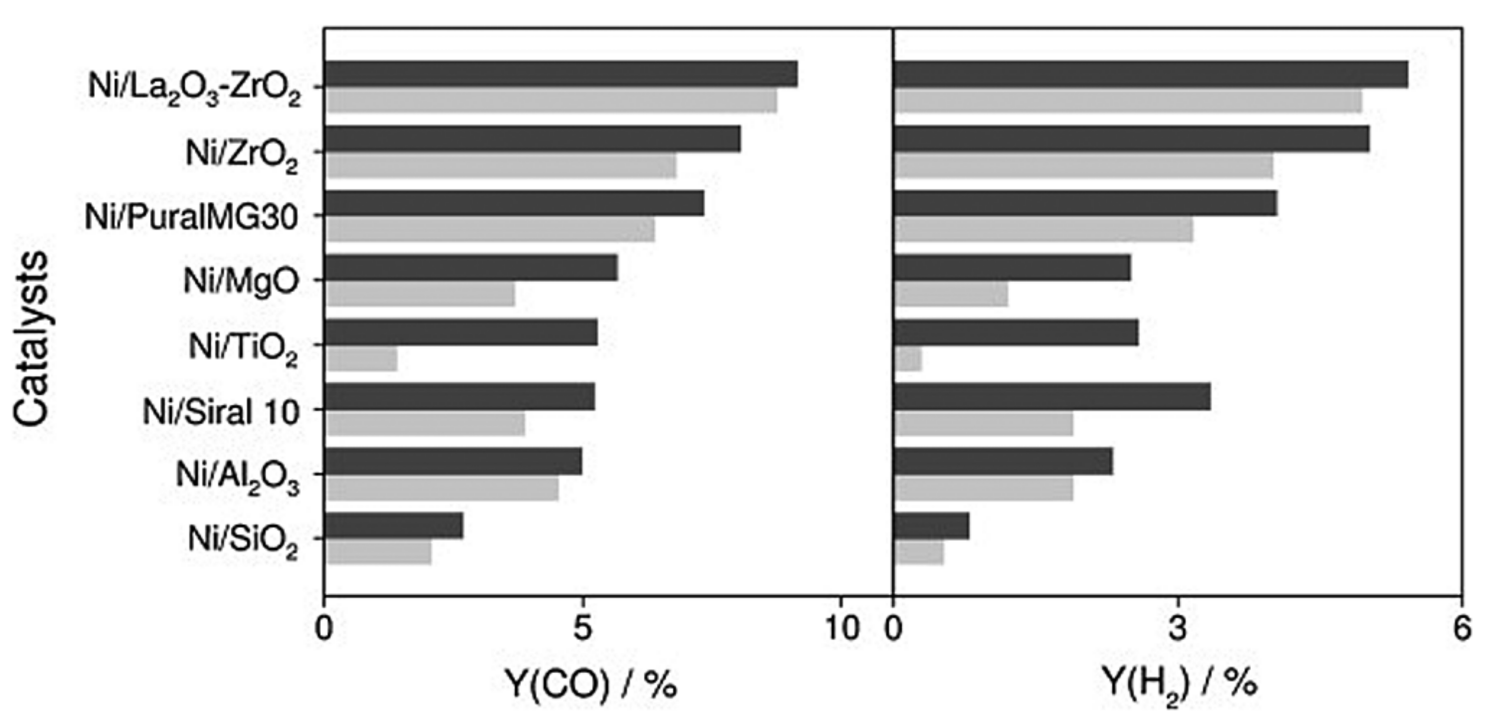

Figure 6. $\mathrm{H}_{2}$ and $\mathrm{CO}$ yields for dry reforming of methane at $400{ }^{\circ} \mathrm{C}$ and GHSV of $7200 \mathrm{~mL} \mathrm{~h}^{-1} \mathrm{~g}_{\text {cat }}{ }^{-1}$ after the first $10 \mathrm{~h}$ (black bars) and $100 \mathrm{~h}$ (gray bars). Adapted with permission from Ref. [44].

Li et al. used a $\mathrm{Ni} / \mathrm{ZrO}_{2}$ catalyst for dry reforming of methane. The results of this study showed high yield and stability for catalysts, which is substantially dependent on the morphologies of the $\mathrm{ZrO}_{2}$ carriers due to their high surface area and good pore size distribution [45]. Zhang et al. investigated the effect of Zr doping on catalysts in the dry reforming of methane. They found that $\mathrm{Zr}$ as a support prevents particle sintering and maintains small particles in Ni-based catalysts through a strong interaction between the metal and support. Zr also prevents Ni migration from the surface into ceria, which increases the active $\mathrm{NiO}$ on the catalyst surface [46]. Moreover, Liu et al. synthesized a multiple-core@shell structured catalyst $\left(\mathrm{Ni}-\mathrm{ZrO}_{2} @ \mathrm{SiO}_{2}\right)$ for methane dry reforming. The results of this study demonstrated the catalysts have high sintering and coking resistance to any coking formation. The results also showed high yield and stability for the catalyst as Ni particle size was not increased even after $240 \mathrm{~h} \mathrm{[47].}$

Another support that is widely used in dry catalyst reforming is $\mathrm{Al}$, more often as aluminum oxide $\left(\mathrm{Al}_{2} \mathrm{O}_{3}\right)$. Ni-based catalysts with $\mathrm{Al}_{2} \mathrm{O}_{3}$ support have been widely applied in dry reforming in recent years due to their low cost, high thermal stability, and benefits to the industry. Sajjadi et al. synthesized $\mathrm{Cu}$ and $\mathrm{Co}$-doped $\mathrm{Ni} / \mathrm{Al}_{2} \mathrm{O}_{3}$ for dry reforming of methane. The results showed $\mathrm{H}_{2}$ production yield of $98.21 \%$ and high stability (1440 min) for $\mathrm{Ni}-\mathrm{Co} / \mathrm{Al}_{2} \mathrm{O}_{3}$ due to the excellent properties of the catalyst such as higher surface area and small particle size [48]. Schwengber et al. used $\mathrm{Ni} / \mathrm{Al}_{2} \mathrm{O}_{3}$ for dry reforming of methane for $\mathrm{H}_{2}$ production. The results illustrated that no remarkable reduction in catalytic activity occurred during the reaction, so no inactivation took place with coke deposition or metal curing [49].

In addition to the supports discussed for Ni-based catalysts, which have been widely used for catalytic dry reforming in recent years, mesoporous supports have also been well tested in recent studies. Mesoporous supports have advantages including prevention of the sintering of metal particles, increased dispersion of $\mathrm{Ni}$ on the catalyst surface, high thermal stability, high conversion of reactants, and high yield [50]. Among the mesoporous supports that have been reported in recent years are meso- $\mathrm{ZrO}_{2}$ [51], meso- $\mathrm{Al}_{2} \mathrm{O}_{3}$ [52,53], meso$\mathrm{La}_{2} \mathrm{O}_{3}$ [54], meso-SiO 2 [55], SBA-15, MCM-41 [56], etc.

Other supports that have been used in recent years for $\mathrm{Ni}$-based catalysts in dry reforming are plant-based polymers. These supports have excellent specifications such as low cost, high degradability, high mechanical strength, and controlled surface chemistry [5]. For example, Zou et al. employed a cellulose-based $\mathrm{Ni} / \mathrm{Al}_{2} \mathrm{O}_{3}$ catalyst as a promising catalyst support for hydrogen production [57]. 


\section{Conclusions and Future Perspectives}

The systematic review and meta-analysis using the combination of ANNs and DE were conducted to predict hydrogen production in catalytic dry reforming from 50 articles, including 100 studies. The role of the DE was to determine the topology of the ANNs (number of hidden layers and neurons in each hidden layer). The ANN was trained using the Adam algorithm. The implementation of this methodology was performed in Python, and different libraries such as Numpy, Pandas, and Keras were used to create, load, and train the topologies identified by the DE algorithm. The best model obtained for the considered three target factors (hydrocarbon conversion, hydrogen yield, and stability test time) had an ARE lower than $3.36 \%$, a fact which indicates good performance. Thus, it can be concluded that the applied methodology provided suitable models that can be further used to generate predictions.

In recent years, much research has been performed on catalytic dry reforming to improve catalyst effectiveness and resistance to coke formation. Various methods have been used to increase the yield of the catalyst including the use of appropriate preparation methods, the use of supports and promoters, the utilization of bimetallic catalysts, etc.

Future research should focus on the use of bimetallic catalysts, including those that are $\mathrm{Ni}$ and Co-based. These catalysts have shown high resistance to coke formation and have high calorific potential to provide reaction heat. A case that needs to be considered in future research is the catalyst particle size because catalysts with the appropriate particle size have better performance.

There is also a need for a special focus on the development of biomass cases as a support for the production of catalysts because these items are very cheap and readily available.

Supplementary Materials: The following are available online at https: / www.mdpi.com/article/ 10.3390/en14102894/s1, Table S1: Extracted data for ANN model development for prediction of hydrogen production in catalytic dry reforming.

Author Contributions: Conceptualization, F.A. and Y.V.; methodology, E.-N.D. and Y.V.; software, E.N.D. and Y.V.; validation, V.T.L. and F.A.; formal analysis, F.A.; investigation, F.A.; resources, V.T.L.; data curation, Y.V.; writing—original draft preparation, V.T.L., E.-N.D., F.A. and Y.V.; writing-review and editing, V.T.L., E.-N.D., F.A. and Y.V.; visualization, F.A.; supervision, F.A.; project administration, Y.V.; funding acquisition, F.A. All authors have read and agreed to the published version of the manuscript.

Funding: The authors acknowledge the financial support from Qatar University, International Research Collaboration Co-funds (IRCC-2020-011). The APC was funded by IRCC-2020-011.

Data Availability Statement: Not applicable.

Conflicts of Interest: The authors declare that they have no known competing financial interests or personal relationships that could have appeared to influence the work reported in this paper.

\section{References}

1. Tran, N.T.; Pham, T.L.M.; Nguyen, T.D.; Van Cuong, N.; Siang, T.J.; Phuong, P.T.; Jalil, A.; Truong, Q.D.; Abidin, S.Z.; Hagos, F.Y.; et al. Improvements in hydrogen production from methane dry reforming on filament-shaped mesoporous alumina-supported cobalt nanocatalyst. Int. J. Hydrog. Energy 2020. [CrossRef]

2. Judd, S.; Al Momani, F.; Znad, H.; Al Ketife, A. The cost benefit of algal technology for combined CO2 mitigation and nutrient abatement. Renew. Sustain. Energy Rev. 2017, 71, 379-387. [CrossRef]

3. Almomani, F.; Al Ketife, A.; Judd, S.; Shurair, M.; Bhosale, R.R.; Znad, H.; Tawalbeh, M. Impact of CO2 concentration and ambient conditions on microalgal growth and nutrient removal from wastewater by a photobioreactor. Sci. Total Environ. 2019, 662, 662-671. [CrossRef]

4. Sun, Y.; Zhang, G.; Xu, Y.; Zhang, R. Dry reforming of methane over Co-Ce-M/AC-N catalyst: Effect of promoters (Ca and Mg) and preparation method on catalytic activity and stability. Int. J. Hydrog. Energy 2019, 44, 22972-22982. [CrossRef]

5. Abdullah, B.; Ghani, N.A.A.; Vo, D.-V.N. Recent advances in dry reforming of methane over Ni-based catalysts. J. Clean. Prod. 2017, 162, 170-185. [CrossRef]

6. Oliveira, A.A.S.; Medeiros, R.L.; Figueredo, G.P.; Macedo, H.P.; Braga, R.M.; Maziviero, F.V.; Melo, M.A.; Melo, D.M.; Vieira, M.M. One-step synthesis of LaNiO3 with chitosan for dry reforming of methane. Int. J. Hydrog. Energy 2018, 43, 9696-9704. [CrossRef] 
7. Almomani, F.; Al-Jaml, K.L.; Bhosale, R.R. Solar photo-catalytic production of hydrogen by irradiation of cobalt co-doped TiO2. Int. J. Hydrog. Energy 2021, 46, 12068-12081. [CrossRef]

8. Bhosale, R.; Kumar, A.; Almomani, F.; Ghosh, U.; Anis, M.S.; Kakosimos, K.; Shende, R.; Rosen, M.A. Solar Hydrogen Production via a Samarium Oxide-Based Thermochemical Water Splitting Cycle. Energies 2016, 9, 316. [CrossRef]

9. Lee, B.; Kim, H.; Lee, H.; Byun, M.; Won, W.; Lim, H. Technical and economic feasibility under uncertainty for methane dry reforming of coke oven gas as simultaneous $\mathrm{H} 2$ production and CO2 utilization. Renew. Sustain. Energy Rev. 2020, 133, 110056. [CrossRef]

10. Ali, S.; Khader, M.M.; Almarri, M.J.; Abdelmoneim, A.G. Ni-based nano-catalysts for the dry reforming of methane. Catal. Today 2020, 343, 26-37. [CrossRef]

11. Abd Ghani, N.A.; Azapour, A.; Syed Muhammad, A.F.A.; Abdullah, B. Dry reforming of methane for hydrogen production over NiCo catalysts: Effect of NbZr promoters. Int. J. Hydrog. Energy 2019, 44, 20881-20888. [CrossRef]

12. Fang, X.; Zhang, J.; Liu, J.; Wang, C.; Huang, Q.; Xu, X.; Peng, H.; Liu, W.; Wang, X.; Zhou, W. Methane dry reforming over $\mathrm{Ni} / \mathrm{Mg}-\mathrm{Al}-\mathrm{O}$ : On the significant promotional effects of rare earth $\mathrm{Ce}$ and $\mathrm{Nd}$ metal oxides. J. CO 2 Util. 2018, 25, 242-253. [CrossRef]

13. Pizzolitto, C.; Pupulin, E.; Menegazzo, F.; Ghedini, E.; Di Michele, A.; Mattarelli, M.; Cruciani, G.; Signoretto, M. Nickel based catalysts for methane dry reforming: Effect of supports on catalytic activity and stability. Int. J. Hydrog. Energy 2019, 44, 28065-28076. [CrossRef]

14. Mohd Arif, N.N.; Abidin, S.Z.; Osazuwa, O.U.; Vo, D.-V.N.; Azizan, M.T.; Taufiq-Yap, Y.H. Hydrogen production via CO2 dry reforming of glycerol over ReNi/CaO catalysts. Int. J. Hydrog. Energy 2019, 44, 20857-20871. [CrossRef]

15. Luisetto, I.; Tuti, S.; Di Bartolomeo, E. Co and Ni supported on CeO2 as selective bimetallic catalyst for dry reforming of methane. Int. J. Hydrog. Energy 2012, 37, 15992-15999. [CrossRef]

16. Andraos, S.; Abbas-Ghaleb, R.; Chlala, D.; Vita, A.; Italiano, C.; Laganà, M.; Pino, L.; Nakhl, M.; Specchia, S. Production of hydrogen by methane dry reforming over ruthenium-nickel based catalysts deposited on $\mathrm{Al} 2 \mathrm{O} 3, \mathrm{MgAl} 2 \mathrm{O} 4$, and YSZ. Int. J. Hydrog. Energy 2019, 44, 25706-25716. [CrossRef]

17. Shang, Z.; Li, S.; Li, L.; Liu, G.; Liang, X. Highly active and stable alumina supported nickel nanoparticle catalysts for dry reforming of methane. Appl. Catal. B Environ. 2017, 201, 302-309. [CrossRef]

18. Akiki, E.; Akiki, D.; Italiano, C.; Vita, A.; Abbas-Ghaleb, R.; Chlala, D.; Ferrante, G.D.; Laganà, M.; Pino, L.; Specchia, S. Production of hydrogen by methane dry reforming: A study on the effect of cerium and lanthanum on $\mathrm{Ni} / \mathrm{MgAl} 2 \mathrm{O} 4$ catalyst performance. Int. J. Hydrog. Energy 2020, 45, 21392-21408. [CrossRef]

19. Drif, A.; Bion, N.; Brahmi, R.; Ojala, S.; Pirault-Roy, L.; Turpeinen, E.; Seelam, P.K.; Keiski, R.L.; Epron, F. Study of the dry reforming of methane and ethanol using Rh catalysts supported on doped alumina. Appl. Catal. A Gen. 2015, 504, 576-584. [CrossRef]

20. Son, I.H.; Lee, S.J.; Roh, H.-S. Hydrogen production from carbon dioxide reforming of methane over highly active and stable $\mathrm{MgO}$ promoted $\mathrm{Co}-\mathrm{Ni} / \gamma-\mathrm{Al} 2 \mathrm{O} 3$ catalyst. Int. J. Hydrog. Energy 2014, 39, 3762-3770. [CrossRef]

21. Harun, N.; Abidin, S.Z.; Osazuwa, O.U.; Taufiq-Yap, Y.H.; Azizan, M.T. Hydrogen production from glycerol dry reforming over Ag-promoted Ni/Al2O3. Int. J. Hydrog. Energy 2019, 44, 213-225. [CrossRef]

22. Abdullah, N.; Ainirazali, N.; Ellapan, H. Structural effect of Ni/SBA-15 by Zr promoter for H2 production via methane dry reforming. Int. J. Hydrog. Energy 2020. [CrossRef]

23. Pan, C.; Guo, Z.; Dai, H.; Ren, R.; Chu, W. Anti-sintering mesoporous Ni-Pd bimetallic catalysts for hydrogen production via dry reforming of methane. Int. J. Hydrog. Energy 2020, 45, 16133-16143. [CrossRef]

24. Le, V.T.; Almomani, F.; Vasseghian, Y.; Vilas-Boas, J.A.; Dragoi, E.-N. Graphene-based nanomaterial for desalination of water: A systematic review and meta-analysis. Food Chem. Toxicol. 2021, 148, 111964. [CrossRef] [PubMed]

25. Vasseghian, Y.; Rad, S.S.; Vilas-Boas, J.A.; Khataee, A. A global systematic review, meta-analysis, and risk assessment of the concentration of vanadium in drinking water resources. Chemosphere 2021, 267, 128904. [CrossRef]

26. Dragoi, E.-N.; Vasseghian, Y. Modeling of mass transfer in vacuum membrane distillation process for radioactive wastewater treatment using artificial neural networks. Toxin Rev. 2020, 1-10. [CrossRef]

27. Khaneghah, A.M.; Farhadi, A.; Nematollahi, A.; Vasseghian, Y.; Fakhri, Y. A systematic review and meta-analysis to investigate the concentration and prevalence of trichothecenes in the cereal-based food. Trends Food Sci. Technol. 2020, 102, 193-202. [CrossRef]

28. Storn, R.; Price, K. Differential Evolution-A Simple and Efficient Heuristic for global Optimization over Continuous Spaces. J. Glob. Optim. 1997, 11, 341-359. [CrossRef]

29. Fernández, J.C.; Hervás, C.; Martínez-Estudillo, F.; Gutiérrez, P.A. Memetic Pareto Evolutionary Artificial Neural Networks to determine growth/no-growth in predictive microbiology. Appl. Soft Comput. 2011, 11, 534-550. [CrossRef]

30. Vasseghian, Y.; Berkani, M.; Almomani, F.; Dragoi, E.-N. Data mining for pesticide decontamination using heterogeneous photocatalytic processes. Chemosphere 2021, 270, 129449. [CrossRef]

31. Abbass, H.A. A Memetic Pareto Evolutionary Approach to Artificial Neural Networks. In AI 2001: Advances in Artificial Intelligence; Stumptner, M., Corbett, D., Brooks, M., Eds.; Springer: Berlin/Heidelberg, Germany, 2001; Volume 2256, pp. 113-152.

32. Volna, E. Neuroevolutionary optimization. Int. J. Comput. Sci. Issues 2010, 7, 31-37. 
33. Vasseghian, Y.; Moradi, M.; Pirsaheb, M.; Khataee, A.; Rahimi, S.; Badi, M.Y.; Mousavi Khaneghah, A. Pesticide decontamination using UV/ferrous-activated persulfate with the aid neuro-fuzzy modeling: A case study of Malathion. Food Res. Int. 2020, 137, 109557. [CrossRef] [PubMed]

34. Moghri, M.; Dragoi, E.N.; Salehabadi, A.; Shukla, D.K.; Vasseghian, Y. Effect of various formulation ingredients on thermal characteristics of PVC/clay nanocomposite foams: Experimental and modeling. e-Polymers 2016, 17, 119-128. [CrossRef]

35. Vasseghian, Y.; Bahadori, A.; Khataee, A.; Dragoi, E.-N.; Moradi, M. Modeling the Interfacial Tension of Water-Based Binary and Ternary Systems at High Pressures Using a Neuro-Evolutive Technique. ACS Omega 2019, 5, 781-790. [CrossRef] [PubMed]

36. Vasseghian, Y.; Ahmadi, M.; Joshaghani, M. Ultrasound Assisted Ash and Sulphur Removal from Bitumen Using Column Flotation Technique: Experimental, RSM and ANN Methods in Modelling and Optimization of Process. Iran. J. Sci. Technol. Trans. A Sci. 2016, 41, 1149-1163. [CrossRef]

37. Dragoi, E.-N.; Curteanu, S.; Leon, F.; Galaction, A.-I.; Cascaval, D. Modeling of oxygen mass transfer in the presence of oxygenvectors using neural networks developed by differential evolution algorithm. Eng. Appl. Artif. Intell. 2011, 24, 1214-1226. [CrossRef]

38. Drăgoi, E.-N.; Curteanu, S.; Lisa, C. A neuro-evolutive technique applied for predicting the liquid crystalline property of some organic compounds. Eng. Optim. 2012, 44, 1261-1277. [CrossRef]

39. Esmaeili, A.; Hejazi, E.; Vasseghian, Y. Comparison study of biosorption and coagulation/air flotation methods for chromium removal from wastewater: Experiments and neural network modeling. RSC Adv. 2015, 5, 91776-91784. [CrossRef]

40. Feoktistov, V. Differential Evolution: In Search of Solutions; Springer: Berlin, Germany, 2006.

41. Vasseghian, Y.; Dragoi, E.-N. Modeling and Optimization of Acid Blue 193 Removal by UV and Peroxydisulfate Process. J. Environ. Eng. 2018, 144, 06018003. [CrossRef]

42. Bian, Z.; Kawi, S. Highly carbon-resistant $\mathrm{Ni}-\mathrm{Co} / \mathrm{SiO} 2$ catalysts derived from phyllosilicates for dry reforming of methane. J. CO2 Util. 2017, 18, 345-352. [CrossRef]

43. Amin, N.A.S.; Yaw, T.C. Thermodynamic equilibrium analysis of combined carbon dioxide reforming with partial oxidation of methane to syngas. Int. J. Hydrog. Energy 2007, 32, 1789-1798. [CrossRef]

44. Sokolov, S.; Kondratenko, E.V.; Pohl, M.-M.; Barkschat, A.; Rodemerck, U. Stable low-temperature dry reforming of methane over mesoporous La2O3-ZrO2 supported Ni catalyst. Appl. Catal. B Environ. 2012, 113-114, 19-30. [CrossRef]

45. Li, W.; Zhao, Z.; Jiao, Y. Dry reforming of methane towards CO-rich hydrogen production over robust supported Ni catalyst on hierarchically structured monoclinic zirconia nanosheets. Int. J. Hydrog. Energy 2016, 41, 17907-17921. [CrossRef]

46. Zhang, F.; Liu, Z.; Chen, X.; Rui, N.; Betancourt, L.E.; Lin, L.; Xu, W.; Sun, C.-J.; Abeykoon, A.M.; Rodriguez, J.A.; et al. Effects of Zr Doping into Ceria for the Dry Reforming of Methane over Ni/CeZrO2 Catalysts: In Situ Studies with XRD, XAFS, and AP-XPS. ACS Catal. 2020, 10, 3274-3284. [CrossRef]

47. Liu, W.; Li, L.; Zhang, X.; Wang, Z.; Wang, X.; Peng, H. Design of Ni-ZrO2@SiO2 catalyst with ultra-high sintering and coking resistance for dry reforming of methane to prepare syngas. J. $\mathrm{CO}_{2}$ Util. 2018, 27, 297-307. [CrossRef]

48. Sajjadi, S.M.; Haghighi, M.; Eslami, A.A.; Rahmani, F. Hydrogen production via CO2-reforming of methane over Cu and Co doped Ni/Al2O3 nanocatalyst: Impregnation versus sol-gel method and effect of process conditions and promoter. J. Sol. Gel Sci. Technol. 2013, 67, 601-617. [CrossRef]

49. Schwengber, C.A.; Da Silva, F.A.; Schaffner, R.A.; Fernandes-Machado, N.R.C.; Ferracin, R.J.; Bach, V.R.; Alves, H.J. Methane dry reforming using $\mathrm{Ni} / \mathrm{Al} 2 \mathrm{O} 3$ catalysts: Evaluation of the effects of temperature, space velocity and reaction time. J. Environ. Chem. Eng. 2016, 4, 3688-3695. [CrossRef]

50. Gnanamani, M.K.; Ribeiro, M.C.; Ma, W.; Shafer, W.D.; Jacobs, G.; Graham, U.M.; Davis, B.H. Fischer-Tropsch synthesis: Metalsupport interfacial contact governs oxygenates selectivity over $\mathrm{CeO} 2$ supported Pt-Co catalysts. Appl. Catal. A Gen. 2011, 393, 17-23. [CrossRef]

51. Zhang, X.; Zhang, Q.; Tsubaki, N.; Tan, Y.; Han, Y. Carbon dioxide reforming of methane over Ni nanoparticles incorporated into mesoporous amorphous ZrO 2 matrix. Fuel 2015, 147, 243-252. [CrossRef]

52. Adamu, S.; Bawah, A.R.; Muraza, O.; Malaibari, Z.; Hossain, M.M. Effects of metal support interaction on dry reforming of methane over Ni/Ce-Al2O3 catalysts. Can. J. Chem. Eng. 2020, 98, 2425-2434. [CrossRef]

53. Newnham, J.; Mantri, K.; Amin, M.H.; Tardio, J.; Bhargava, S.K. Highly stable and active Ni-mesoporous alumina catalysts for dry reforming of methane. Int. J. Hydrog. Energy 2012, 37, 1454-1464. [CrossRef]

54. Li, K.; Chang, X.; Pei, C.; Li, X.; Chen, S.; Zhang, X.; Assabumrungrat, S.; Zhao, Z.-J.; Zeng, L.; Gong, J. Ordered mesoporous $\mathrm{Ni} / \mathrm{La} 2 \mathrm{O} 3$ catalysts with interfacial synergism towards CO2 activation in dry reforming of methane. Appl. Catal. B Environ. 2019, 259, 118092. [CrossRef]

55. Huang, F.; Wang, R.; Yang, C.; Driss, H.; Chu, W.; Zhang, H. Catalytic performances of Ni/mesoporous SiO2 catalysts for dry reforming of methane to hydrogen. J. Energy Chem. 2016, 25, 709-719. [CrossRef]

56. Wang, N.; Yu, X.; Wang, Y.; Chu, W.; Liu, M. A comparison study on methane dry reforming with carbon dioxide over LaNiO3 perovskite catalysts supported on mesoporous SBA-15, MCM-41 and silica carrier. Catal. Today 2013, 212, 98-107. [CrossRef]

57. Zou, J.; Yang, H.; Zeng, Z.; Wu, C.; Williams, P.T.; Chen, H. Hydrogen production from pyrolysis catalytic reforming of cellulose in the presence of K alkali metal. Int. J. Hydrog. Energy 2016, 41, 10598-10607. [CrossRef] 